\title{
PROFIL FITOKIMIA DAN UJI AKTIVITAS ANTIFUNGI EKSTRAK METANOL DAUN LABAN (Vitex pinnata L.) SERTA FRAKSI-FRAKSINYA
}

Rizkiyani Zulfa Larasati, Irma Ratna Kartika, dan Fera Kurniadewi Jurusan Kimia Fakultas Matematika dan Ilmu Pengetahuan Alam Universitas Negeri Jakarta, Jl. Pemuda No.10, Rawamangun 13320, Jakarta, Indonesia

\begin{abstract}
Abstrak
Penelitian ini bertujuan untuk mendapatkan data profil fitokimia dan data bioktivitas antifungi ekstrak $\mathrm{MeOH}$, fraksi $n$-heksana, fraksi $\mathrm{CHCl}_{3}$ dan fraksi EtOAc daun laban (Vitex pinnata L.) asal pantai Pangandaran terhadap fungi Candida albicans dan Trichophyton mentagrophytes. Ekstraksi daun laban dilakukan dengan metode maserasi dan partisi bertingkat. Uji fitokimia dilakukan melalui uji profil fitokimia dan pengamatan KLT terhadap ekstrak $\mathrm{MeOH}$, fraksi $n$-heksana, fraksi $\mathrm{CHCl}_{3}$, fraksi EtOAc. Dari hasil uji fitokimia dan identifikasi golongan senyawa dengan KLT diperoleh informasi bahwa ekstrak $\mathrm{MeOH}$ daun laban mengandung metabolit sekunder golongan flavonoid, fenolik, steroid dan terpenoid. Fraksi $n$-heksana mengandung metabolit sekunder golongan steroid. Fraksi $\mathrm{CHCl}_{3}$ mengandung metabolit sekunder golongan flavonoid, fenolik dan steroid. Sedangkan fraksi EtOAc mengandung metabolit sekunder golongan fenolik dan terpenoid. Uji aktivitas antifungi dilakukan dengan metode difusi dan dilusi agar. Hasil uji aktivitas antifungi menunjukkan nilai DDH dan KHM terbaik dimiliki oleh fraksi EtOAc dengan nilai DDH rata-rata mencapai 15,5 mm pada konsentrasi $50 \%$ dan nilai KHM sebesar 3,1\% terhadap Trichophyton mentagrophytes. Diduga metabolit sekunder golongan terpenoid berperan penting dalam aktivitas antifungi pada ekstrak EtOAc terhadap Trichophyton mentagrophytes.
\end{abstract}

Kata kunci: Vitex pinnata L., fitokimia, Kromatografi Lapis Tipis, antifungi, Candida albicans, Trichophyton mentagrophytes, Diameter Daerah Hambat, Konsentrasi Hambat Minimum.

\begin{abstract}
The objective of this research are to obtain phytochemical profile data and antifungal bioactivity data from $\mathrm{MeOH}$ extract, $n$-hexane fraction, $\mathrm{CHCl}_{3}$ fraction and EtOAc fraction of Laban leaves (Vitex pinnata L.) from Pangandaran beach to against Trichophyton mentagrophytes and Candida albicans. Laban leaves extraction is done by maceration method and multilevel partitioning. Phytochemical test is done through testing and screening of phytochemistry profile by $\mathrm{TLC}$ to the $\mathrm{MeOH}$ extract, $n$-hexane fraction, $\mathrm{CHCl}_{3}$ fraction and EtOAc fraction. The results and identification of phytochemical classes compounds with TLC obtained information that the $\mathrm{MeOH}$ extract of laban leaves containing secondary metabolites such as flavonoids, phenolics, steroids and terpenoids. N-hexane fraction containing secondary metabolites steroids. $\mathrm{CHCl}_{3} \mathrm{fractions}$ containing secondary metabolites such as flavonoids, phenolics and steroids. EtOAc fraction containing secondary metabolites such as phenolics and terpenoids. Antifungal activity test was taken by diffusion and dilution methods. Antifungal activity test results showed the best MIC and DDH value owned by EtOAc fraction with $D D H$ values averaged $15.5 \mathrm{~mm}$ at a concentration of $50 \%$ and the MIC values of $3.1 \%$ against Trichophyton mentagrophytes. Classes of terpenoid secondary metabolites was expected have a role to antifungal activity against Trichophyton mentagrophytes in EtOAc extract.
\end{abstract}

Key words: Vitex pinnata L., phytochemical, Thin Layer Chromatography, antifungal, Candida albicans, Trichophyton mentagrophytes, Diameter Inhibitory Region, Minimum Inhibitory Concentration.

\section{Pendahuluan}

Genus Vitex merupakan bagian dari famili Verbenaceae yang terdiri dari sekitar 270 spesies berupa pohon dan semak-semak yang banyak terdapat di daerah tropis dan subtropis termasuk Indonesia. Salah satu spesies dari genus Vitex yang ada di Indonesia adalah laban (Vitex pinnata L.). Tanaman laban (Vitex pinnata L.) telah diketahui mempunyai khasiat sebagai obat antifungi karena secara tradisional daun laban (Vitex pinnata L.) dapat digunakan untuk mengobati sakit kulit seperti luka dan kudis. Selain itu daun laban juga dapat digunakan untuk menurunkan demam. Adanya aktivitas antifungi dari laban (Vitex pinnata L.) juga telah dibuktikan secara ilmiah, yaitu melalui penelitian yang dilakukan oleh Ata et al. [1] yang menemukan bahwa pada 
batang tanaman laban (Vitex pinnata L.) terkandung senyawa pinnatosida yang bersifat antifungi terhadap Candida albicans.

Candida albicans merupakan salah satu fungi penyebab infeksi. Penyakit infeksi yang disebabkan oleh Candida albicans dikenal dengan nama kandidiasis yaitu penyakit pada selaput lendir, mulut, vagina dan saluran pencernaan [2]. Spesies fungi lain yang juga menjadi penyebab infeksi adalah Trichophyton mentagrophytes. Fungi ini menyerang kulit halus (glabourus skin) seperti yang terdapat pada daerah muka, badan, dan lengan. Penyakit yang disebabkan oleh fungi ini dikenal dengan istilah dermatofitosis yaitu penyakit pada daerah yang mengandung zat tanduk seperti kuku, rambut dan stratum korneum pada epidermis [3].

Penelitian lain mengenai vitex sebagai antifungi juga telah dilakukan oleh Maurya et al. [4] dan Gautam et al. [5] yang menemukan bahwa ekstrak etanol dan metanol dari daun Vitex negundo Linn memperlihatkan adanya sifat antifungi. Adapun senyawa yang diperkirakan memiliki sifat antifungi dari daun Vitex negundo Linn tersebut adalah senyawa Negundosid yang merupakan kelompok senyawa iridoid glikosida.

Penemuan senyawa yang bersifat antifungi dari suatu tanaman perlu mendapat perhatian sebab sampai saat ini bahan kimia yang dapat menghambat fungi patogen pada manusia masih sedikit dan cenderung bersifat toksik [6]. Oleh karena itu, perlu dikembangkan obat antifungi lain yang lebih efektif dengan tingkat toksisitas yang rendah [7].

Penelitian ini dilakukan untuk mengetahui profil fitokimia dan potensi antifungi dari ekstrak metanol $(\mathrm{MeOH})$ daun laban (Vitex pinnata $L$.) serta fraksi-fraksinya, yaitu fraksi $n$ heksana, fraksi $\mathrm{CHCl}_{3}$ dan fraksi EtOAc terhadap fungi Candida albicans dan Trichophyton mentagrophytes.

\section{Metodologi Penelitian}

Alat-alat yang digunakan antara lain: alatalat gelas yang biasa digunakan di Laboratorium Kimia dan Mikologi, heating mantle, rotary evaporator EYELA, bejana KLT, lampu uv, oven BINDER FD23, autoklaf THRUSOFT TAC-60, inkubator BINDER BD240, laminar air flow, corong kaca, pipet tetes, batang pengaduk, spatula, termometer, statif dan klem, cawan kaca, kawat ose, tabung reaksi, rak tabung reaksi, pipet Pasteur, api Bunsen, dan balon karet pipet. Bahan-bahan yang digunakan antara lain: berbagai pelarut dengan kualifikasi teknis yang telah didistilasi ( $\mathrm{MeOH}, \mathrm{CHCl}_{3}$, EtOAc dan $n$-heksana), DMSO, $\mathrm{HCl}_{(\mathrm{p})}$, anhidrida asam asetat, pereaksi $\mathrm{FeCl}_{3}$, pereaksi Dragendorff, pereaksi Liebermann Burchard, pereaksi cerium sulfat, serbuk $\mathrm{Mg}$, $\mathrm{H}_{2} \mathrm{SO}_{4(\mathrm{p})}$, kertas saring dan plat KLT silica gel GF 245 (Merck). Untuk uji antifungi menggunakan media SDA (Sabaouraud Dextrose Agar) dan antibiotik krim ketokonazol $2 \%$ serta suspensi nistatin $100.000 \mathrm{IU} / \mathrm{mL}$.

Sampel tanaman yang diuji yaitu daun laban (Vitex pinnata L.) diperoleh dari daerah pantai Pangandaran yang kemudian diekstraksi secara maserasi dengan pelarut metanol $(\mathrm{MeOH})$. Setelah dihasilkan ekstrak $\mathrm{MeOH}$ daun laban (Vitex pinnata L.), selanjutnya dilakukan uji fitokimia, partisi ekstrak dengan pelarut $n$-heksana, $\mathrm{CHCl}_{3}$ dan EtOAc, skrining fitokimia dengan KLT dan uji aktivitas antifungi. Fungi uji yang digunakan, yaitu Candida albicans dan Trichophyton mentagrophytes yang diperoleh dari Laboratorium mikologi BBALITVET Bogor.

Uji profil fitokimia yang dilakukan terhadap ekstrak $\mathrm{MeOH}$ daun laban yang meliputi uji terhadap golongan alkaloid, flavonoid, fenolik, saponin, steroid dan terpenoid. Uji alkaloid dilakukan dengan menggunakan metode Culvenor dan Fitzgerald. Sebanyak 5-10 mL 
Tabel 1. Hasil Uji Fitokimia

\begin{tabular}{ccc}
\hline No & $\begin{array}{c}\text { Golongan } \\
\text { Senyawa }\end{array}$ & $\begin{array}{l}\text { Kandungan dalam } \\
\text { ekstrak kering daun } \\
\text { Vitex pinnata }\end{array}$ \\
\hline 1 & Alkaloid & - \\
2 & Flavonoid & + \\
3 & Fenolik & + \\
4 & Saponin & + \\
5 & Terpenoid & - \\
6 & Steroid & + \\
\hline Keterangan tabel: + : ada zat aktif yang terdeteksi \\
\end{tabular}

ekstrak MeOH daun laban (Vitex pinnata L.) ditambahkan 0,5-1 $\mathrm{mL}$ asam sulfat $2 \mathrm{~N}$ dan dikocok sampai terbentuk dua lapisan. Lapisan asam (atas) dipipet dan dimasukkan kedalam tabung reaksi, selanjutnya ditambahkan dua tetes pereaksi Dragendorf. Adanya senyawa alkaloid ditandai dengan terbentuknya endapan bewarna jingga sampai coklat pada tabung reaksi[8].

Uji flavonoid dilakukan dengan menggunakan pereaksi Willstater/Sianidin. Sebanyak $2 \mathrm{~mL}$ ekstrak $\mathrm{MeOH}$ daun laban (Vitex pinnata L.) dimasukkan ke dalam tabung reaksi dan ditambah dengan $0,5 \mathrm{~mL}$ asam klorida pekat $(\mathrm{HCl}$ pekat) dan serbuk $\mathrm{Mg}$ seujung spatula. Adanya flavonoid ditandai dengan warna merah, jingga dan hijau tergantung pada struktur flavonoid yang terkandung dalam sampel tersebut[8].

Uji fenolik dilakukan dengan menggunakan pereaksi $\mathrm{FeCl}_{3} 1 \%$. Sebanyak $2 \mathrm{~mL}$ ekstrak $\mathrm{MeOH}$ daun laban (Vitex pinnata L.) dimasukkan ke dalam tabung reaksi dan ditambah $0,5 \mathrm{~mL} \mathrm{FeCl} 31 \%$. Adanya senyawa fenolik ditunjukkan dengan terbentuknya warna biru, ungu sampai hitam[8].

Uji saponin dilakukan dengan cara mengocok kuat $2 \mathrm{~mL}$ ekstrak $\mathrm{MeOH}$ daun laban (Vitex pinnata L.) dalam tabung reaksi. Adanya saponin ditunjukkan dengan terbentuknya busa yang tetap selama 15 menit dan tidak hilang dengan penambahan asam klorida pekat[8].

Uji Terpenoid dan Steroid dilakukan dengan menambahkan 2-3 tetes anhidrida asam asetat dan 1-2 tetes $\mathrm{H}_{2} \mathrm{SO}_{4}$ pekat pada sampel. Adanya terpenoid ditandai dengan terbentuknya warna merah-ungu. Adanya steroid ditandai dengan terbentuknya hijaubiru. Keberadaan kedua senyawa ditandai dengan terbentuknya warna merah dengan biru-ungu berbentuk cincin di tengah[8].

(a) (b)

(c)

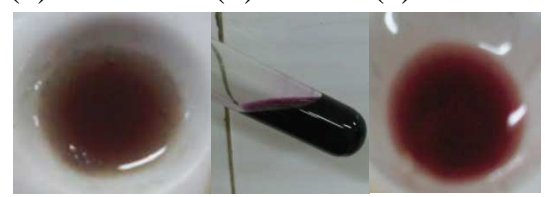

Gambar 1.

Hasil Uji Fitokimia Ekstrak MeOH Daun Laban (Vitex pinnata L.) Positif Mengandung Metabolit Sekunder Golongan (a) Flavonoid, (b) Fenolik, dan (c) Terpenoid

Karakterisasi fitokimia dari masing-masing ekstrak dan fraksi dilakukan melalui pengamatan Kromatografi Lapis Tipis (KLT) untuk mengetahui kandungan metabolit sekunder yang terkandung di dalamnya. Fasa diam yang digunakan adalah plat KLT silica gel GF 245 berukuran $5 \times 5 \mathrm{~cm}$. Eluen yang digunakan berupa eluen tunggal dan eluen campuran dengan variasi perbandingan $(2,5: 7,5 ; 1: 1$ : dan 7,5:2,5). Elusi dilakukan setelah chamber KLT penuh dengan uap eluen, yaitu dengan didiamkan sekitar 5-10 menit. Kemudian menotolkan ekstrak kasar pada garis batas salah satu ujung plat KLT dan dibiarkan mengelusi. Setelah sampai pada garis batas atas, plat KLT dikeringkan di udara 
Tabel 2. Hasil Karakterisasi Fitokimia Ekstrak $\mathrm{MeOH}$, Fraksi $n$-heksana, Fraksi $\mathrm{CHCl}_{3}$ dan Fraksi EtOAc Daun Laban (Vitex pinnata L.)

\begin{tabular}{|c|c|c|c|c|c|c|c|c|}
\hline \multirow[b]{2}{*}{ No } & \multirow{2}{*}{$\begin{array}{l}\text { Sampel } \\
\text { (Ekstrak/ } \\
\text { Fraksi) } \\
\text { Daun } \\
\text { laban }\end{array}$} & \multirow[b]{2}{*}{ Noda } & \multirow[b]{2}{*}{$\mathrm{Rf}$} & \multicolumn{4}{|c|}{$\begin{array}{l}\text { Warna noda dengan pereaksi } \\
\text { penyemprot }\end{array}$} & \multirow[b]{2}{*}{ Hasil } \\
\hline & & & & $\begin{array}{c}\text { noda } \\
\text { dengan } \\
\text { pengamata } \\
\text { n UV }\end{array}$ & $\mathrm{FeCl}_{3}$ & $\begin{array}{l}\text { Cerium } \\
\text { sulfat }\end{array}$ & $\begin{array}{l}\text { Liebermann- } \\
\text { Burchard }\end{array}$ & \\
\hline \multirow[t]{6}{*}{1} & $\mathrm{MeOH}$ & 1 & 0,125 & Kuning & - & Coklat & - & Flavonoid \\
\hline & & 2 & 0,15 & Kuning & - & - & Merah & Terpenoid \\
\hline & & 3 & 0,2 & $\begin{array}{l}\text { Hijau } \\
\text { muda }\end{array}$ & - & - & Hijau & Steroid \\
\hline & & 4 & 0,275 & $\begin{array}{l}\text { Hijau } \\
\text { muda }\end{array}$ & Hitam & - & - & Fenolik \\
\hline & & 5 & 0,45 & $\begin{array}{l}\text { Hijau } \\
\text { muda }\end{array}$ & - & - & Hijau & Steroid \\
\hline & & 6 & 0,625 & $\begin{array}{l}\text { Hijau } \\
\text { muda }\end{array}$ & - & - & Hijau & Steroid \\
\hline \multirow[t]{3}{*}{2} & $n-$ & 1 & 0,25 & Hijau & Hijau & Hijau & Hijau & Steroid \\
\hline & heksana & 2 & 0,45 & Hijau & Hijau & Hijau & Hijau-biru & Steroid \\
\hline & & 3 & 0,625 & Hijau & Hijau & Hijau & Hijau-biru & Steroid \\
\hline \multirow[t]{3}{*}{3} & $\mathrm{CHCl}_{3}$ & 1 & 0,125 & $\begin{array}{l}\text { Sedikit } \\
\text { merah }\end{array}$ & Coklat & $\begin{array}{l}\text { Sedikit } \\
\text { coklat }\end{array}$ & - & Flavonoid \\
\hline & & 2 & 0,2 & Kuning & Hijau & Hijau & Hijau & Steroid \\
\hline & & 3 & 0,275 & Hijau & Hitam & Hitam & Hitam & Fenolik \\
\hline \multirow[t]{2}{*}{4} & EtOAc & 1 & 0,1 & $\begin{array}{l}\text { Sedikit } \\
\text { ungu }\end{array}$ & Hitam & - & Coklat & Fenolik \\
\hline & & 2 & 0,15 & $\begin{array}{l}\text { Sedikit } \\
\text { ungu }\end{array}$ & - & - & Merah & Terpenoid \\
\hline
\end{tabular}

terbuka dan diamati bercak noda hasil pemisahan di bawah lampu UV. Selanjutnya plat KLT disemprot dengan zat penampak noda (larutan Liebermann Burchard untuk steroid dan triterpenoid, $\mathrm{FeCl}_{3} 1 \%$ untuk fenolik, dan cerium sulfat $2 \%$ untuk flavonoid). Nilai Rf dapat dihitung dari kromatogram.

Uji aktivitas antifungi secara in vitro dilakukan di Laboratorium Mikologi Balai Besar Penelitian Veteriner (BBALITVET). Uji aktivitas antifungi dilakukan dengan metode difusi secara sumuran dan dilusi dengan penipisan agar lempeng. Cara difusi agar dilakukan untuk mengamati adanya aktivitas antifungi dari ekstrak yang diuji, dan dilanjutkan dengan cara pengenceran tuang (pouring dilution method) untuk menentukan konsentrasi hambat minimal (KHM). Adanya aktivitas antifungi dari ekstrak dapat dilihat dari terbentuknya daerah hambat yang berupa zona bening pada medium agar yang ditanami jamur uji di sekitar larutan ekstrak. Daerah hambat yang terbentuk diukur sebagai Diameter Daerah Hambat (DDH).

Jamur yang diuji dibiakkan secara strik pada permukaan agar Sabouraud di cawan petri, lalu dibuat lubang-lubang sumuran dengan pipet Pasteur, dan masing-masing ekstrak/fraksi daun laban (Vitex pinnata L.) serta kontrol dimasukkan ke dalam lubang sampai merata ke permukaan media. Inkubasi dilakukan pada suhu $37^{\circ} \mathrm{C}$ dan hasilnya dapat dilihat setelah 5 hari untuk Trichophyton mentagrophytes dan 2 hari untuk Candida albicans. Untuk menentukan KHM, ekstrak diencerkan dengan 5 taraf konsentrasi masing- 


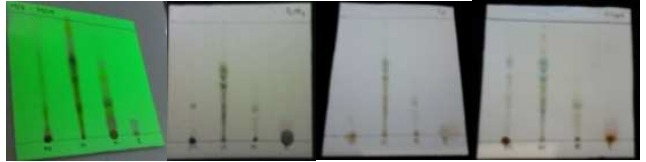

Gambar 1. Hasil Uji Fitokimia Ekstrak MeOH Daun Laban (Vitex pinnata L.) Positif Mengandung Metabolit Sekunder Golongan (a) Flavonoid, (b) Fenolik, dan (c) Terpenoid

masing 50\%; 25\%; 12,5\%; 6,2 dan 3,1. Untuk ekstrak EtOAc dibuat 3 taraf konsentrasi tambahan yaitu 1,$6 ; 0,8$ dan 0,4 pada uji penentuan KHM. Jamur uji ditanam di media Sabouraud Dekstrose Agar (SDA) tabung miring secara strik, dan diinkubasi pada suhu $37^{\circ} \mathrm{C}$ selama 5 hari untuk $T$. mentagrophytes dan 2 hari untuk $C$. albicans. Koloni jamur dilarutkan dengan air suling steril sebanyak 5 $\mathrm{ml}$ dan diencerkan secara seri, dengan cara menyediakan 2 buah tabung steril, masingmasing diisi dengan air suling steril sebanyak 9 $\mathrm{ml}$. Sebanyak $1 \mathrm{ml}$ larutan jamur diambil, dan dimasukkan ke dalam tabung pertama, campur merata (enceran $10^{-1}$ ) lalu dari tabung pertama diambil $1 \mathrm{ml}$ dan dimasukkan ke dalam tabung kedua hingga didapat enceran $10^{-2}$. Masing-masing sebanyak $1 \mathrm{~mL}$ enceran ekstrak dan jamur uji $\left(10^{-2}\right)$ dituangkan ke dalam cawan petri steril. Percobaan dilakukan dengan 2 kali ulangan. Media agar Sabouraud Dextrose Agar (SDA) yang masih cair dituangkan ke dalam setiap cawan, dan diratakan. Kemudian diinkubasi selama 5 hari untuk Trichophyton mentagrophytes dan 2 hari untuk Candida albicans. Koloni jamur yang tumbuh dihitung jumlahnya, dan konsentrasi terkecil dari ektrak/ fraksi daun laban (Vitex pinnata L.) yang tidak menunjukkan adanya pertumbuhan koloni ditentukan sebagai Konsentrasi Hambat Minimal (KHM).

\section{Hasil dan Pembahasan}

Hasil uji fitokimia terhadap ekstrak $\mathrm{MeOH}$ daun laban menunjukkan hasil positif terhadap kandungan metabolit sekunder golongan flavonoid, fenolik dan terpenoid dapat dilihat pada Tabel 1 dan Gambar 1 . Sementara itu, karakteristik fitokimia ekstrak $\mathrm{MeOH}$, fraksi $n$-heksana, fraksi $\mathrm{CHCl}_{3}$, fraksi
EtOAc daun laban dilakukan dengan mengamati hasil KLT di bawah sinar UV dan dengan mengamati warna yang dihasilkan setelah dilakukan penyemprotan dengan pereaksi penampak noda. Pereaksi penampak noda yang digunakan yaitu $\mathrm{FeCl}_{3}$, Cerium sulfat, dan Liebermann-Burchard. Hasil karakterisasi golongan metabolit sekunder yang terkandung dalam ekstrak $\mathrm{MeOH}$, fraksi $n$-heksana, fraksi $\mathrm{CHCl}_{3}$ dan fraksi EtOAc daun laban yang dilakukan melaui pengamatan hasil pemisahan pada KLT dengan eluen campuran $n$-heksana dan EtOAc $(7,5: 2,5)$ dapat dilihat pada Tabel 2 dan Gambar 2.

Berdasarkan data pada Tabel 2 diketahui bahwa pada ekstrak $\mathrm{MeOH}$ diduga terkandung metabolit sekunder golongan flavonoid, fenolik, terpenoid, dan steroid yang ditandai dengan terbentuknya noda coklat setelah dilakukan penyemprotan dengan reagen cerium sulfat untuk identifikasi flavonoid, noda hitam setelah dilakukan penyemprotan dengan $\mathrm{FeCl}_{3}$ untuk identifikasi fenolik, noda merah dan hijau setelah dilakukan penyemprotan dengan reagen LiebermannBurchard untuk identifikasi terpenoid dan steroid. Pada fraksi $n$-heksana diduga terkandung 3 komponen metabolit sekunder golongan steroid yang ditandai dengan terbentuknya noda hijau-biru setelah dilakukan penyemprotan dengan reagen Liebermann-Burchard. Pada fraksi $\mathrm{CHCl}_{3}$ diduga terkandung metabolit sekunder golongan flavonoid, steroid dan fenolik yang ditandai dengan terbentuknya noda coklat setelah dilakukan penyemprotan dengan reagen cerium sulfat untuk identifikasi flavonoid, noda hijau setelah penyemprotan dengan reagen Liebermann-Burchard untuk identifikasi steroid dan noda hitam setelah penyemprotan dengan reagen $\mathrm{FeCl}_{3}$ untuk identifikasi fenolik. Pada fraksi EtOAc diduga terkandung metabolit sekunder golongan terpenoid dan fenolik yang ditandai dengan 
Tabel 3. Hasil Uji Pendahuluan Aktivitas Antifungi Ekstrak MeOH, Fraksi $n$-heksana, Fraksi $\mathrm{CHCl}_{3}$ dan Fraksi EtOAc Daun Laban (Vitex pinnata L.) serta Kontrol terhadap Candida albicans dan Trichophyton mentagrophytes

\begin{tabular}{ccccc}
\hline & \multicolumn{4}{c}{ Jenis Fungi } \\
\cline { 2 - 5 } Sampel Uji & \multicolumn{2}{c}{ Candida albicans } & \multicolumn{2}{c}{$\begin{array}{c}\text { Trichophyton } \\
\text { mentagrophytes }\end{array}$} \\
\cline { 2 - 5 } & Cawan 1 & Cawan 2 & Cawan 1 & Cawan 2 \\
\hline Ekstrak MeOH, 50\% & - & - & + & + \\
Fraksi $n$ - Heksana, 50\% & - & - & - & - \\
Fraksi CHCl $3,50 \%$ & - & - & + & + \\
Fraksi EtOAc, 50\% & - & - & + & + \\
Ketokonazol, 2\% & + & + & + & + \\
Nistatin, 100000 IU/mL & + & + & + & - \\
DMSO & - & - & - & +
\end{tabular}

Keterangan :(-) tidak terbentuk zona bening $(+)$ terbentuk zona bening

terbentuknya noda merah setelah penyemprotan dengan reagen Liebermannburchard untuk identifikasi terpenoid dan noda hitam setelah penyemprotan dengan reagen $\mathrm{FeCl}_{3}$ untuk identifikasi fenolik.

Hasil yang diperoleh dari uji pendahuluan aktivitas antifungi ekstrak dan fraksi daun laban dapat dilihat pada Tabel 3.

Berdasarkan data pada Tabel 3, ekstrak $\mathrm{MeOH}$, fraksi $n$-Heksana, fraksi $\mathrm{CHCl}_{3}$ dan fraksi EtOAc tidak memperlihatkan adanya aktivitas antifungi terhadap Candida albicans. Sedangkan kontrol positif krim ketokonazol memperlihatkan adanya zona hambat parsial rata-rata sebesar 22,5 $\mathrm{mm}$ dan nistatin menghasilkan zona hambat total sebesar 12 mm. Namun, ketika masing-masing ekstrak dan fraksi diuji terhadap Trichophyton mentagrophytes mulai terlihat adanya aktivitas antifungi dari ekstrak $\mathrm{MeOH}$, fraksi $\mathrm{CHCl}_{3}$ dan fraksi EtOAc yang ditandai dengan terbentuknya zona hambat. Walaupun besarnya tidak sebanding dengan yang dihasilkan kontrol positif krim ketokonazol 2\% yang menghasilkan zona hambat total ratarata sebesar $36 \mathrm{~mm}$. Oleh karena itu, pada uji pengukuran DDH dan penentuan KHM selanjutnya hanya dilakukan pada ekstrak
$\mathrm{MeOH}$, fraksi $\mathrm{CHCl}_{3}$, dan fraksi EtOAc terhadap Trichophyton mentagrophytes saja.

Selanjutnya dilakukan Pengukuran Diameter Daerah Hambat (DDH) dilakukan dengan metode difusi secara sumuran, yang diisi dengan berbagai konsentrasi sampel ekstrak uji yang memperlihatkan adanya aktivitas antifungi berdasarkan hasil uji pendahuluan. Konsentrasi ekstrak yang digunakan merupakan hasil pengenceran (dilusi) dari konsentrasi 50\% menjadi konsentrasi 25\%; 12,5\%; 6,2\% dan 3,1\%. Hasil pengukuran Diameter Daerah Hambat (DDH) ekstrak metanol $\mathrm{MeOH}, \mathrm{CHCl}_{3}$, dan EtOAc daun laban (Vitex pinnata L.) terhadap pertumbuhan Trichophyton mentagrophytes dapat dilihat pada Tabel 4.

Dari hasil pengukuran DDH terhadap masingmasing fraksi daun laban diketahui bahwa fraksi EtOAc menghasilkan nilai DDH rata-rata terbesar yaitu sebesar 15,5 $\mathrm{mm}$ pada konsentrasi $50 \%$ dan besar nilai $\mathrm{DDH}$ yang dihasilkan pada konsentrasi $12,5 \%$ setara dengan nistatin. Sehingga dapat diduga bahwa ekstrak dan fraksi yang menunjukkan adanya aktivitas antifungi terhadap Trichophyton mentagrophytes memiliki mekanisme penghambatan mirip nistatin yang merupakan suatu antibiotik turunan polien. Hal ini terlihat 
Tabel 4.

Hasil Pengukuran DDH Ekstrak $\mathrm{MeOH}$, Fraksi $\mathrm{CHCl}_{3}$ dan Fraksi EtOAc Daun Laban (Vitex pinnata L.) dan Kontrol terhadap Trichophyton mentagrophytes

\begin{tabular}{|c|c|c|c|c|}
\hline \multirow{4}{*}{ Sampel Uji } & \multirow{4}{*}{ Konsentrasi } & & & \multirow{4}{*}{$\begin{array}{c}\text { Rata-rata } \\
(\mathrm{mm})\end{array}$} \\
\hline & & \multirow{2}{*}{\multicolumn{2}{|c|}{$\begin{array}{c}\text { Trichophyton } \\
\text { mentagrophytes } \\
\text { Diameter Daerah } \\
\text { Hambat }(\mathrm{mm}) \\
\text { Ulangan }\end{array}$}} & \\
\hline & & & & \\
\hline & & 1 & 2 & \\
\hline & $50 \%$ & 12 & 13 & 12,5 \\
\hline Ekstrak & $25 \%$ & 11 & 10 & 10,5 \\
\hline \multirow[t]{4}{*}{$\mathrm{MeOH}$} & $12,5 \%$ & 10 & 10 & 10 \\
\hline & $6,2 \%$ & 8 & 7 & 7,5 \\
\hline & $3,1 \%$ & 6 & 6 & 6 \\
\hline & $50 \%$ & 15 & 13 & 14 \\
\hline Fraksi & $25 \%$ & 12 & 14 & 13 \\
\hline \multirow[t]{4}{*}{$\mathrm{CHCl}_{3}$} & $12,5 \%$ & 11 & 10 & 10,5 \\
\hline & $6,2 \%$ & 8 & 7 & 7,5 \\
\hline & $3,1 \%$ & 6 & 7 & 6,5 \\
\hline & $50 \%$ & 16 & 15 & 15,5 \\
\hline Fraksi & $25 \%$ & 13 & 14 & 13,5 \\
\hline \multirow[t]{3}{*}{ EtOAc } & $12,5 \%$ & 13 & 12 & 12,5 \\
\hline & $6,2 \%$ & 10 & 10 & 10 \\
\hline & $3,1 \%$ & 10 & 10 & 10 \\
\hline $\begin{array}{c}\text { Ketokonazo } \\
\text { । }\end{array}$ & $2 \%$ & 32 & 33 & 32,5 \\
\hline Nistatin & $\begin{array}{c}100000 \\
\mathrm{IU} / \mathrm{mL}\end{array}$ & 12 & 12 & 12 \\
\hline DMSO & & 0 & 0 & 0 \\
\hline
\end{tabular}

dari rata-rata ukuran DDH yang dihasilkan lebih mendekati DDH nistatin.

Hasil perhitungan jumlah koloni pada uji penentuan Konsentrasi Hambat Minimum (KHM) ekstrak $\mathrm{MeOH}, \mathrm{CHCl}_{3}$, dan EtOAc daun laban (Vitex pinnata L.) terhadap pertumbuhan Trichophyton mentagrophytes dapat dilihat pada Tabel 5.

Berdasarkan data pada Tabel 5 dapat dilihat bahwa ekstrak EtOAc memiliki nilai KHM yang paling kecil yaitu 3,1\% dibandingkan dengan fraksi $\mathrm{CHCl}_{3}$ dan ekstrak $\mathrm{MeOH}$. Hal ini menunjukkan bahwa aktivitas antifungi fraksi EtOAc terhadap Trichophyton mentagrophytes lebih baik dibandingkan fraksi $\mathrm{CHCl}_{3}$ dan ekstrak $\mathrm{MeOH}$ karena dalam konsentrasi yang lebih kecil dibandingkan fraksi $\mathrm{CHCl}_{3}$ dan ekstrak $\mathrm{MeOH}$, fraksi EtOAc dapat menghambat pertumbuhan fungi Trichophyton mentagrophytes.

Berdasarkan hasil uji profil fitokimia dan hasil uji aktivitas antifungi terhadap ekstrak $\mathrm{MeOH}$, fraksi $n$-heksana, fraksi $\mathrm{CHCl}_{3}$ dan fraksi EtOAc dapat diduga bahwa metabolit sekunder golongan terpenoid berperan penting dalam aktivitas antifungi Trichophyton mentagrophytes sebab berdasarkan penelitian yang telah dilakukan oleh Gautam [5] diketahui bahwa senyawa negundosid dari daun Vitex negundo Linn menunjukkan aktivitas antifungi termasuk dalam kelompok senyawa iridoid glikosida yang merupakan turunan senyawa terpenoid.

Selain itu, apabila dibandingkan dengan kontrol positif yang digunakan terlihat bahwa ekstrak dan fraksi daun laban (Vitex pinnata L.) yang menunjukkan aktivitas antifungi terhadap Trichophyton mentagrophytes memiliki nilai DDH yang setara dengan antibiotik nistatin. Sehingga dapat diduga bahwa mekanisme antifungi yang dimiliki oleh senyawa yang bersifat antifungi pada daun laban (Vitex pinnata L.) mirip dengan nistatin yang merupakan antibiotik turunan polien.

\section{Kesimpulan dan Saran}

Berdasarkan hasil penelitian dan pembahasan, diperoleh kesimpulan bahwa:

1. Profil fitokimia ekstrak metanol dan fraksi-fraksi daun laban berdasarkan hasil uji fitokimia dan pengamatan KLT adalah sebagai berikut:

- Ekstrak metanol terdiri dari senyawa golongan flavonoid, fenolik, terpenoid dan steroid.

- Fraksi $n$-heksana terdiri dari senyawa golongan steroid.

- Fraksi $\mathrm{CHCl}_{3}$ terdiri dari senyawa golongan flavonoid, fenolik dan steroid.

- Fraksi EtOAc terdiri dari senyawa golongan fenolik dan terpenoid. 
Tabel 5. Hasil Perhitungan Jumlah Koloni pada Uji Penentuan $\mathrm{KHM}$ Ekstrak $\mathrm{MeOH}$, Fraksi $\mathrm{CHCl}_{3}$ dan Fraksi EtOAc Daun Laban (Vitex pinnata L.) terhadap Pertumbuhan Trichophyton mentagrophytes

\begin{tabular}{|c|c|c|c|c|}
\hline \multirow{4}{*}{ Sampel Uji } & \multirow{4}{*}{$\begin{array}{c}\text { Konsentr } \\
\text { asi }\end{array}$} & \multicolumn{2}{|c|}{ Fungi Uji } & \multirow{4}{*}{$\begin{array}{c}\text { Rata- } \\
\text { rata } \\
\text { (CFU/m } \\
\text { L) }\end{array}$} \\
\hline & & \multirow{2}{*}{\multicolumn{2}{|c|}{$\begin{array}{c}\text { Trichophyton } \\
\text { mentagrophyt } \\
\text { es } \\
\text { Jumlah Koloni } \\
\text { (CFU/mL) } \\
\text { Ulangan }\end{array}$}} & \\
\hline & & & & \\
\hline & & 1 & 2 & \\
\hline & $50 \%$ & 0 & 0 & 0 \\
\hline Ekstrak & $25 \%$ & 0 & 0 & 0 \\
\hline \multirow{4}{*}{$\mathrm{MeOH}$} & $12,5 \%$ & 45 & 50 & 47,5 \\
\hline & $6,2 \%$ & 115 & 112 & 113,5 \\
\hline & $3,1 \%$ & 254 & 260 & 257 \\
\hline & $50 \%$ & 0 & 0 & 0 \\
\hline Fraksi & $25 \%$ & 0 & 0 & 0 \\
\hline \multirow[t]{4}{*}{$\mathrm{CHCl}_{3}$} & $12,5 \%$ & 0 & 0 & 0 \\
\hline & $6,2 \%$ & 0 & 0 & 0 \\
\hline & $3,1 \%$ & 125 & 130 & 127,5 \\
\hline & $50 \%$ & 0 & 0 & 0 \\
\hline Fraksi & $25 \%$ & 0 & 0 & 0 \\
\hline \multirow[t]{6}{*}{ EtOAc } & $12,5 \%$ & 0 & 0 & 0 \\
\hline & $6,2 \%$ & 0 & 0 & 0 \\
\hline & $3,1 \%$ & 0 & 0 & 0 \\
\hline & $1,6 \%$ & 55 & 55 & 55 \\
\hline & $0,8 \%$ & 219 & 217 & 218 \\
\hline & $0,4 \%$ & 370 & 370 & 370 \\
\hline $\begin{array}{c}\text { Ketokonaz } \\
\text { ol }\end{array}$ & $2 \%$ & 0 & 0 & 0 \\
\hline Nistatin & $\begin{array}{l}100000 \\
\mathrm{IU} / \mathrm{mL}\end{array}$ & 0 & 0 & 0 \\
\hline Kontrol (-) & & 434 & 443 & 438,5 \\
\hline
\end{tabular}

2. Ekstrak $\mathrm{MeOH}$, fraksi $n$-heksana, fraksi $\mathrm{CHCl}_{3}$ dan fraksi EtOAc daun laban (Vitex pinnata $L$.) tidak memiliki daya hambat terhadap Candida albicans.

3. Ekstrak $\mathrm{MeOH}$, fraksi $\mathrm{CHCl}_{3}$ dan fraksi EtOAc daun Laban (Vitex pinnata L.) memiliki daya hambat terhadap Trichophyton mentagrophytes sementara fraksi $n$-heksana tidak.

4. Fraksi EtOAc daun laban menunjukkan aktivitas penghambatan yang paling baik dibandingkan fraksi $\mathrm{CHCl}_{3}$, ekstrak
$\mathrm{MeOH}$ dan fraksi $n$-heksana dengan nilai DDH rata-rata mencapai $15,5 \mathrm{~mm}$ pada konsentrasi 50\% serta nilai KHM sebesar $3,1 \%$ dan diduga memiliki mekanisme penghambatan terhadap Trichophyton mentagrophytes yang mirip dengan antibiotik nistatin.

5. Diduga senyawa yang berperan sebagai antifungi pada daun laban (Vitex pinnata L.) merupakan senyawa metabolit sekunder golongan terpenoid serta turunannya.

Untuk lebih menyempurnakan hasil penelitian mengenai aktivitas antifungi dari daun laban (Vitex pinnata L.), maka :

1. Perlu dilakukan penelitian untuk menentukan mekanisme antifungi yang lebih pasti dari ekstrak $\mathrm{MeOH}$, fraksi $\mathrm{CHCl}_{3}$, dan fraksi EtOAc daun laban (Vitex pinnata L.) terhadap Trichophyton mentagrophytes.

2. Perlu dilakukan penelitian untuk mengisolasi senyawa murni yang bersifat antifungi dari fraksi EtOAc.

3. Perlu dilakukan penelitian tentang aktivitas antifungi ekstrak dan fraksi daun laban (Vitex pinnata L.) terhadap fungi penyebab penyakit kulit dan penyakit sistemik lainnya.

\section{Ucapan Terima Kasih}

Penulis mengucapkan terima kasih kepada Ibu Irma Ratna Kartika M. Sc, Tech dan Ibu Dr. Fera Kurniadewi, M. Si yang telah banyak membantu dan membimbing selama penelitian dan penyusunan skripsi. Juga kepada rekan Tim Vitex pinnata, lin dan Venessa serta seluruh pihak yang telah membantu selama penelitian dan penyelesaia skripsi. 


\section{Daftar Pustaka}

[1] Ata, A., Nathan, M., Chad, D. I. dan Samarasekera, R. 2009. Minor chemical constituents of Vitex pinnata. Nat Prod Commun, 4(1):1-4.

[2] Pelczar, M.J dan Chan, E. C. S. 2008. Dasar-Dasar Mikrobiologi 1. Diterjemahkan oleh: Hadioetomo, R. S, Imas, T., Tjitrosomo, S.S. dan Angka, S. L. Universitas Indonesia Press, Jakarta: 189-98, 206, 522.

[3] Hamzah, M., Aisah, S. 2007. Ilmu Penyakit Kulit dan Kelamin. Edisi V. UI.Press, Jakarta: 87-90.

[4] Maurya, R., Shukla, P. K. dan Ashok, K . 2007. New Antifungal Flavonoid Glycoside from Vitex negundo. Bioorganic and Medical Chemistry. 17: 239-242.

[5] Gautam, L. N.2008. Chemical Constituents from Vitex negundo (Linn.) of Nepalese Origin. Scientific World. 6: 6.

[6] Simatupang, M. M. 2009. Candida Albicans. Departemen Mikrobiologi Fakultas Kedokteran USU, Sumatra Utara: 14-15.

[7] Katzung B. G. 1998. Farmakologi Dasar dan Klinik. Edisi IV. EGC, Jakarta: 699, 753-5.

[8] Harborne, J. B.1996. Metode Fitokimia. Penerbit ITB, Bandung: 123-129. 